\title{
Crescimento de meloeiro e acúmulo de nutrientes na planta sob irrigação com águas salinas
}

\author{
Michelangelo de O. Silva ${ }^{1}$, Maria B. G. dos S. Freire', Alessandra M. S. Mendes ${ }^{2}$, \\ Fernando J. Freire ${ }^{1}$, Carlos E. S. de Sousa ${ }^{1} \&$ Gleidson B. de Góes ${ }^{3}$
}

\begin{abstract}
RESUMO
Neste trabalho, utilizaram-se 4 tipos de solo da região de Mossoró, RN, tradicionalmente cultivados com meloeiro, irrigados com soluções preparadas para corresponderem a oito valores de condutividade elétrica (CE $=100,250,500,750$, $1250,1750,2250$ e $\left.3000 \mu \mathrm{S} \mathrm{cm}^{-1}\right)$, e dois de relação de adsorção de sódio [RAS $=4$ e $12\left(\mathrm{mmol} \mathrm{L}^{-1}\right)^{1 / 2}$ ], combinados como tratamentos de salinidade; assim, o experimento foi arranjo fatorial $4 \times 8 \times 2$ (quatro solos, oito CE e duas RAS), em três repetições, contabilizando-se 192 unidades experimentais. O delineamento experimental foi em blocos casualizados, com uma repetição por bloco. Avaliaram-se variáveis de planta (produção de matéria fresca e seca da parte aérea e composição mineral). A produção de matéria fresca e seca de meloeiro foi reduzida com o aumento da salinidade da água nos dois cultivos sucessivos, causando morte das plantas no segundo cultivo, poucos dias após o transplantio. O incremento da salinidade da água promoveu elevação nos conteúdos acumulados de $\mathrm{Ca}, \mathrm{Mg}, \mathrm{Na}, \mathrm{K}$ e $\mathrm{Cl}$ nas planta de meloeiro.
\end{abstract}

Palavras-chave: salinidade, RAS, Cucumis melo L.

\section{Cantaloupe growth and accumulation of nutrients in the plant under saline water irrigation}

\begin{abstract}
This study was conducted in a greenhouse at the Environmental Sciences Department of the Federal Rural University for the Semi-Árid. Four soil types, traditionally used for cantaloupe production in the Mossoró Region, were used and irrigated with solutions corresponding to eight electrical conductivities $(E C=100 ; 250 ; 500 ; 750 ; 1,250 ; 1,750 ; 2,250$ and $\left.3,000 \mu \mathrm{S} \mathrm{cm}^{-1}\right)$ and two sodium adsorption ratios [SAR $=4$ and $\left.12\left(\mathrm{mmol} \mathrm{L}^{-1}\right)^{1 / 2}\right]$, combined as salinity treatments. The experiment was a factorial arrangement of $4 \times 8 \times 2$ (four soils, eight EC and two SAR), with three replicates, and 192 experimental units, in a randomized block design. Plant characteristics (fresh and dry matter production and mineral composition) were evaluated. Fresh and dry cantaloupe production was reduced with increased water salinity in two successive crops, leading to plant death a few days after transplanting in the second cycle. Increased water salinity elevated $\mathrm{Ca}, \mathrm{Mg}, \mathrm{Na}, \mathrm{K}$ and $\mathrm{Cl}$ accumulation in the plants. Saline water use increased salinity and sodicity of all studied soils, diminishing cantaloupe growth.
\end{abstract}

Key words: salinity, SAR, Cucumis melo L.

1 Departamento de Agronomia/UFRPE, Rua Dom Manoel de Medeiros s/n, Dois Irmãos CEP 52171-900, Recife, PE. Fone: (81) 3320-6242, Fax: (81) 3320-6220 E-mail: betania@depa.ufrpe.br

2 Embrapa Semi-Árido, BR 428, km 152, Zona Rural, CP 23, CEP 56302-970, Petrolina, PE. Fone: (87) 3862-1711. E-mail: asalvianobr@yahoo.com.br

3 UFERSA, BR 110, km 47, Bairro Pres. Costa e Silva, CEP 59625-900, Mossoró, RN. Fone: (84) 321-3846. E-mail: gleidsongoes@hotmail.com 


\section{INTRODUÇÃO}

O problema da salinidade em áreas irrigadas se agrava quando o balanço de sais revela maior entrada que saída, promovendo acréscimo da concentração salina na área considerada, condições em que a água de irrigação, além de contribuir para o aumento da concentração salina pode, também, provocar a elevação do lençol freático que, através de ascensão capilar, passa a fornecer água e sais à zona radicular.

A quantidade de sais adicionados ao solo via irrigação, é proporcional à quantidade de água aplicada, ou seja, a concentração de sais no solo cresce em função da lâmina de irrigação aplicada. Atualmente, a principal causa do aumento da salinização dos solos agrícolas tem sido as irrigações mal manejadas. O excesso de fertilização, o uso de água salina e a ausência de drenagem adequada, são fatores que resultam em situações desfavoráveis que podem favorecer a degradação de solos.

O acúmulo de sais no solo está intimamente relacionado com o processo de evapotranspiração. Conforme a água é absorvida pelas plantas ou evapora na superfície do solo, os sais se acumulam. A maneira pela qual os sais são transportados e acumulados no perfil do solo, depende da quantidade e da qualidade da água de irrigação o que, em junção com os fatores ambientais, como evapotranspiração, seqüência de cultivos e intensidade e distribuição das chuvas, promove o desenvolvimento de um perfil salino característico para diferentes tipos de solo.

Na região produtora de meloeiro do Estado do Rio Grande do Norte, a água utilizada para irrigação provém de poços artesianos profundos que, embora de boa qualidade, apresenta alto custo de obtenção, o que impossibilita o seu uso por grande parte dos produtores e os fazem buscar fontes alternativas de água, como poços abertos no calcário Jandaíra, reduzindo consideravelmente seu custo; entretanto, esta fonte de água tem o inconveniente de apresentar teores elevados de sais podendo trazer, como conseqüência, a salinização dos solos e decréscimo no rendimento das culturas mais sensíveis; além disso, devido à elevada concentração de bicarbonato de cálcio na água, pode ocorrer elevação da alcalinidade do solo (Oliveira \& Maia, 1998; Medeiros et al., 2003).

O excesso de sais no solo reduz a disponibilidade de água para as plantas além de trazer problemas pelo efeito de íons tóxicos específicos, a ponto de afetar seu rendimento e a qualidade da produção (USSL Staff, 1954; Meiri et al., 1982; Alencar et al., 2003; Farias et al., 2003).
O meloeiro é uma cultura exigente em temperaturas noturnas e diurnas elevadas durante todo o seu ciclo de cultivo, pois altas temperaturas e baixa umidade relativa do ar elevam consideravelmente o teor de açúcares nas frutas, tornando-os mais saborosos e aromáticos, consistentes e com maior vida útil pós-colheita; essas características justificam o sucesso da cultura em regiões de climas quentes, como a região Nordeste, especificamente no Estado do Rio Grande do Norte (Farias et al., 2003; Mendonça et al., 2004).

Desta forma se objetivou, neste trabalho, avaliar o crescimento de meloeiro e o acúmulo de elementos nas plantas, em quatro solos do Rio Grande do Norte, irrigados com águas de níveis crescentes de condutividade elétrica (CE) e relação de adsorção de sódio (RAS).

\section{MATERIAL E MÉTODOS}

Amostras de solo coletadas no Agropolo Assu/Mossoró, no Rio Grande do Norte, em áreas tradicionalmente cultivadas com meloeiro, foram utilizadas, coletadas e analisadas 20 amostras, selecionando-se quatro solos: Cambissolo Háplico Ta Eutrófico típico - (CXve), Argissolo Vermelho Distrófico arênico - (PVd), Latossolo Vermelho-Amarelo Eutrófico argissólico - (LVAe), e Neossolo Flúvico Ta Eutrófico típico - (RYve). As amostras de solo foram coletadas do horizonte superficial, na profundidade de 0-30 cm; após a coleta, essas foram secadas ao ar, destorroadas e passadas em peneira de $2 \mathrm{~mm}$ para a caracterização física e química (Tabelas 1 e 2), e de $4 \mathrm{~mm}$, para montagem do experimento; foram estudados, também, quatro solos da região irrigados com soluções preparadas para corresponderem a oito valores de CE e dois de RAS, combinados como tratamentos de salinidade. Assim, o experimento correspondeu a um arranjo fatorial $4 \times 8 \times 2$ (quatro solos, oito valores de CE e dois de RAS), em três repetições, contabilizando 192 unidades experimentais. O delineamento experimental foi em blocos casualizados, com uma repetição por bloco.

As faixas de CE das águas aplicadas se assemelharam às águas comumente encontradas na região, com valores de 100, 250, 500, 750, 1.250, 1.750, 2.250 e $3.000 \mu \mathrm{S} \mathrm{cm}^{-1}$, classificadas como $C_{1}, C_{2}, C_{3}$ e $C_{4}$ que, segundo USSL Staff (1954), estão associadas, respectivamente, a baixo, médio, alto e muito alto risco de salinização em águas de irrigação. Nesta faixa de CE estudada se incluem, também, as águas usadas em irrigação no Nordeste do Brasil, em sua maioria (Oliveira \& Maia, 1998; Medeiros et al., 2003). As referidas

Tabela 1. Atributos físicos das amostras do Cambissolo Háplico (CXve), Argissolo Vermelho (PVd), Latossolo Vermelho-Amarelo (LVAe) e Neossolo Flúvico (RYve) estudados na profundidade de 0-30 cm

\begin{tabular}{|c|c|c|c|c|c|c|c|c|c|c|c|}
\hline \multirow{3}{*}{ Solo } & \multirow{2}{*}{ Areia } & \multirow{2}{*}{ Silte } & \multirow{2}{*}{ Argila } & \multirow{2}{*}{$\mathrm{ADA}^{(1)}$} & \multirow{2}{*}{$\mathrm{GF}^{(2)}$} & \multirow{2}{*}{$\mathrm{GD}^{(3)}$} & \multicolumn{2}{|c|}{ Densidade } & \multicolumn{3}{|c|}{ Porosidade } \\
\hline & & & & & & & Solo & Partículas & Macro & Micro & Total \\
\hline & \multicolumn{4}{|c|}{$\mathrm{g} \mathrm{kg}^{-1}$} & \multicolumn{2}{|c|}{$\%$} & \multicolumn{2}{|c|}{$\mathrm{g} \mathrm{cm}^{-3}$} & \multicolumn{3}{|c|}{$\%$} \\
\hline CXve & 502 & 234 & 264 & 84 & 68 & 32 & 1,46 & 2,47 & 8 & 32 & 40 \\
\hline PVd & 893 & 14 & 93 & 21 & 86 & 14 & 1,70 & 2,45 & 19 & 12 & 31 \\
\hline LVAe & 810 & 42 & 148 & 55 & 41 & 59 & 1,68 & 2,43 & 13 & 19 & 32 \\
\hline RYve & 252 & 500 & 248 & 21 & 91 & 9 & 1,40 & 2,55 & 5 & 48 & 53 \\
\hline
\end{tabular}

${ }^{1}$ Argila dispersa em água; ${ }^{2}$ Grau de floculação; ${ }^{3}$ Grau de dispersão. Fonte: EMBRAPA (1997) 
águas foram preparadas na forma de soluções de $\mathrm{NaCl}$ e $\mathrm{CaCl}_{2}$, nos valores de 4 e 12 de RAS para todas as soluções, correspondendo também à maioria das águas de irrigação utilizadas no Nordeste, com baixo risco de sodificação, especialmente para a região em estudo.

O trabalho foi conduzido em casa de vegetação do Departamento de Ciências Ambientais da Universidade Federal Rural do Semi-Árido, Mossoró, RN. O experimento foi montado em vasos de polietileno com capacidade de $10 \mathrm{dm}^{3}$, perfurados na base, com vistas à instalação de drenos para coleta do lixiviado; a fim de evitar perdas de solo, os orifícios foram recobertos com espuma.

Tabela 2. Atributos químicos das amostras do Cambissolo Háplico (CXve), Argissolo Vermelho (PVd), Latossolo Vermelho-Amarelo (LVAe) e Neossolo Flúvico (RYve) estudados na profundidade de 0-30 cm

\begin{tabular}{|c|c|c|c|c|}
\hline \multirow{2}{*}{ Atributo } & \multicolumn{4}{|c|}{ Solo } \\
\hline & CXve & PVd & LVAe & RYve \\
\hline $\mathrm{pH}(1: 2,5)$ & 7,20 & 5,40 & 7,10 & 8,10 \\
\hline $\mathrm{CEe}^{(1)}\left(\mathrm{dS} \mathrm{m}^{-1}\right)$ & 0,20 & 0,10 & 0,10 & 0,65 \\
\hline C.0. $\left(\mathrm{g} \mathrm{kg}^{-1}\right)$ & 6,30 & 4,30 & 2,54 & 8,60 \\
\hline $\mathrm{Ca}^{2+}\left(\mathrm{cmol}_{\mathrm{c}} \mathrm{dm}^{-3}\right)$ & 2,40 & 0,90 & 2,20 & 12,60 \\
\hline $\mathrm{Mg}^{2+}\left(\mathrm{cmol}_{\mathrm{c}} \mathrm{dm}^{-3}\right)$ & 0,80 & 0,40 & 0,80 & 4,25 \\
\hline $\mathrm{Na}^{+}\left(\mathrm{cmol}_{\mathrm{c}} \mathrm{dm}^{-3}\right)$ & 0,16 & 0,05 & 0,04 & 1,10 \\
\hline $\mathrm{K}^{2+}\left(\mathrm{cmol}_{\mathrm{c}} \mathrm{dm}^{-3}\right)$ & 0,53 & 0,10 & 0,22 & 0,98 \\
\hline $\mathrm{CTC}^{(2)}\left(\mathrm{cmol}_{\mathrm{c}} \mathrm{dm}^{-3}\right)$ & 7,25 & 4,98 & 4,66 & 14,98 \\
\hline $\mathrm{PST}^{(3)}(\%)$ & 2,21 & 1,00 & 0,86 & 7,34 \\
\hline $\mathrm{P}_{\text {Mehlich }}\left(\mathrm{mg} \mathrm{dm}^{-3}\right)$ & 16,00 & 5,00 & 19,00 & 42,00 \\
\hline $\mathrm{P}_{\text {Olsen }}\left(\mathrm{mg} \mathrm{dm}^{-3}\right)$ & 8,00 & 3,50 & 10,50 & 31,00 \\
\hline$P_{\text {Rem }}\left(m g ~ L^{-1}\right)$ & 31,20 & 46,60 & 48,80 & 35,00 \\
\hline \multicolumn{5}{|l|}{ Extrato da pasta: } \\
\hline $\mathrm{pH}$ & 7,10 & 5,90 & 6,50 & 7,90 \\
\hline $\mathrm{CEes}^{(4)}\left(\mathrm{dS} \mathrm{m}^{-1}\right)$ & 0,53 & 0,28 & 0,62 & 0,96 \\
\hline $\mathrm{Ca}^{2+}\left(\mathrm{cmol}_{\mathrm{c}} \mathrm{L}^{-1}\right)$ & 0,75 & 0,25 & 1,00 & 1,00 \\
\hline $\mathrm{Mg}^{2+}\left(\mathrm{cmol}_{\mathrm{c}} \mathrm{L}^{-1}\right)$ & 0,13 & 0,00 & 0,13 & 0,13 \\
\hline $\mathrm{Na}^{+}\left(\mathrm{cmol}_{\mathrm{c}} \mathrm{L}^{-1}\right)$ & 0,14 & 0,09 & 0,15 & 0,15 \\
\hline $\mathrm{K}^{+}\left(\mathrm{cmol}_{\mathrm{c}} \mathrm{L}^{-1}\right)$ & 0,03 & 0,03 & 0,05 & 0,05 \\
\hline $\mathrm{Cl}^{-}\left(\mathrm{cmol}_{\mathrm{c}} \mathrm{L}^{-1}\right)$ & 0,25 & 0,15 & 0,50 & 0,55 \\
\hline $\mathrm{CO}_{3}^{2-}\left(\mathrm{cmol}_{\mathrm{c}} \mathrm{L}^{-1}\right)$ & 0,00 & 0,10 & 0,00 & 0,00 \\
\hline $\mathrm{HCO}_{3}^{-}\left(\mathrm{cmol}_{\mathrm{c}} \mathrm{L}^{-1}\right)$ & 0,75 & 0,88 & 0,75 & 0,88 \\
\hline $\mathrm{SO}_{4}^{2-}\left(\mathrm{cmol}_{\mathrm{c}} \mathrm{L}^{-1}\right)$ & 0,00 & 0,00 & 0,00 & 0,00 \\
\hline
\end{tabular}

${ }^{1}$ Condutividade elétrica do extrato $1: 1 ;{ }^{2}$ Capacidade de troca de cátions; ${ }^{3}$ Percentagem de sódio trocável; ${ }^{4}$ Condutividade elétrica do extrato de saturação; Análises realizadas conforme metodologia recomendada por USSL Staff (1954)

As amostras de solo preparadas foram acondicionadas nos vasos, com uma massa de $10 \mathrm{~kg} \mathrm{vaso}^{-1}$, recebendo irrigação com as respectivas soluções preestabelecidas para atender à demanda da planta $(80 \%$ da capacidade máxima de retenção de umidade do solo) e um volume adicional para proporcionar a lixiviação, correspondendo a 50\% do volume de poros de cada solo. As sementes de meloeiro do tipo amarelo, cultivar Mandacaru, foram semeadas em bandejas de 128 células com substrato comercial, para a obtenção das mudas, como de costume na região; depois de acondicionadas as amostras de solo nos vasos, realizou-se a primeira irrigação e, no mesmo dia, as mudas de meloeiro, com 8 a 15 dias após a semeadura, foram transplantadas, deixando-se uma planta por vaso, conduzindo-as em haste única por tutoramento. Fez-se uma adubação para todos os tratamentos com o propósito de suprir as necessidades da cultura, de acordo com as análises químicas e as exigências nutricionais para cada fase de desenvolvimento do meloeiro; aos 45 dias após o plantio, as plantas foram coletadas, cortando-se $1 \mathrm{~cm}$ acima da superfície do solo, pesando-as em seguida para obtenção da matéria fresca (MF), acondicionando-as em sacos de papel e levando-as para secar em estufa de circulação forçada a $65^{\circ} \mathrm{C}$, durante $48 \mathrm{~h}$ ou até adquirirem peso constante; após a secagem, o material foi pesado para obtenção da matéria seca (MS) e, em seguida, triturado em moinho, depois guardado para posterior análise.

Após a coleta, o solo foi preparado para receber as mudas, para o segundo cultivo porém, por motivo de falta de mudas, o transplantio demorou sete dias; após este período, seguiram-se todos os procedimentos descritos para o primeiro cultivo (plantio, desbaste e irrigação); durante o tempo em que o solo permaneceu sem receber irrigação e com maior evaporação, começou-se a observar o aparecimento de manchas brancas no Neossolo Flúvico e pontos esbranquiçados nos outros solos estudados.

No segundo cultivo, após oito dias das plantas transplantadas, começou-se a observar tombamento e morte nas plantas, com sintomas de toxidez por salinidade (murcha de plantas ainda verdes, amarelecimento, com necrose internerval e nas bordas das folhas, das mais velhas para as mais novas). As plantas foram retiradas e acondicionadas em sacos de papel e levadas para estufa, por 48 h, ou até adquirirem peso constante; foram pesadas para obtenção da matéria seca (MS), em seguida trituradas em moinho e guardadas para análises posteriores. Aos vinte dias após o transplantio se retiraram as plantas que restavam, seguindo-se o procedimento descrito para o primeiro cultivo.

As amostras de planta foram submetidas a extração nitro-perclórica para determinação dos teores de Ca, Mg, Na e K (Malavolta et al., 1989) e o Cl foi extraído em água (Bezerra Neto \& Barreto, 2004). As variáveis foram submetidas a análise da variância e teste de Tukey a 5\% de probabilidade para comparação das médias entre os tratamentos de RAS; ajustaram-se, também, equações de regressão das variáveis dependentes em função dos tratamentos de condutividade elétrica aplicados, visando-se obter estimativas de dados de produção e de acúmulo de elementos nas plantas com o uso de águas de irrigação com diferentes níveis de sais, para os fatores principais (solo e RAS).

\section{RESULTADOS E DISCUSSÃO}

A medida em que a concentração de sais das soluções de percolação foi aumentando, deu-se decréscimo na produção de matéria fresca e seca, para todos os solos estudados (Tabela 3), comprovando-se o efeito limitante da salinidade na produtividade do meloeiro. Esses mesmos resultados foram encontrados por Farias et al. (2003), observando que as plantas irrigadas com águas de níveis de salinidade crescentes apresentaram menor produção de matéria fresca e seca aos 
45 dias de cultivo. A menor produção de matéria fresca e seca das plantas do meloeiro para os níveis de salinidade mais elevados, reflete o efeito do potencial osmótico da solução do solo, inibindo a absorção de água pela planta e, conseqüentemente, reduzindo seu crescimento.

A RAS não interferiu na produção de matéria fresca e seca das plantas, exceto para o Neossolo Flúvico (Tabela 3); o mesmo foi constatado para os conteúdos de $\mathrm{Ca}, \mathrm{Mg}, \mathrm{Na}, \mathrm{K}$ e $\mathrm{Cl}$ acumulados nas plantas; apenas o conteúdo de $\mathrm{K}$ acumulado nas plantas cultivadas no Argissolo Vermelho foi superior na RAS 4 em relação à RAS 12, enquanto no Neossolo Flúvico o aumento da RAS de 4 para 12 proporcionou aumento no acúmulo de Na e K nas plantas de meloeiro no primeiro cultivo; apesar de nesse solo o acúmulo de Na ter aumentado, as plantas também apresentaram elevados conteúdos de Ca e Mg e mesmo o K também foi superior ao Na; assim, o maior acúmulo de Na não chegou a afetar a produção de matéria fresca e seca das plantas; ao contrário, refletiu um leve incremento dessa produção.

Avaliando a produção ao longo do ciclo da cultura, Souza et al. (2003) observaram que a produção de matéria fresca e seca aumentou com o incremento da salinidade da água

Tabela 3. Produção(1) de matéria fresca (MF), matéria seca (MS) e conteúdos de $\mathrm{Ca}, \mathrm{Mg}, \mathrm{Na}, \mathrm{K}$ e $\mathrm{Cl}$ no primeiro cultivo de plantas de meloeiro irrigadas com águas de percolação de RAS diferentes nos quatro solos estudados

\begin{tabular}{|c|c|c|c|c|c|}
\hline \multirow{2}{*}{ Variável } & \multirow{2}{*}{ RAS } & \multicolumn{4}{|c|}{ Solo } \\
\hline & & CXve & PVd & LVAe & RYve \\
\hline \multirow{3}{*}{$\begin{array}{c}\text { MF } \\
\left(\text { g planta }{ }^{-1}\right)\end{array}$} & 4 & $136,99 \mathrm{a}$ & $65,49 \mathrm{a}$ & $107,97 \mathrm{a}$ & $183,37 b$ \\
\hline & 12 & $135,06 \mathrm{a}$ & $58,71 \mathrm{a}$ & $103,89 \mathrm{a}$ & $193,76 \mathrm{a}$ \\
\hline & Média & $136,03 \mathrm{~B}$ & $62,11 \mathrm{D}$ & $105,93 \mathrm{C}$ & $184,23 \mathrm{~A}$ \\
\hline \multicolumn{6}{|c|}{ CV $-12,83 \%$} \\
\hline \multirow{3}{*}{$\begin{array}{c}\text { MS } \\
\left(\mathrm{g} \mathrm{planta}^{-1}\right)\end{array}$} & 4 & 13,62 a & $5,67 \mathrm{a}$ & 8,99 a & $17,98 \mathrm{~b}$ \\
\hline & 12 & $13,41 \mathrm{a}$ & $4,73 \mathrm{a}$ & $8,27 \mathrm{a}$ & $18,50 \mathrm{a}$ \\
\hline & Média & $13,52 \mathrm{~B}$ & $5,21 \mathrm{D}$ & $8,63 \mathrm{C}$ & $17,71 \mathrm{~A}$ \\
\hline \multicolumn{6}{|c|}{ CV $-15,57 \%$} \\
\hline \multirow{4}{*}{$\begin{array}{c}\text { Ca } \\
\left(m g \text { planta }{ }^{-1}\right)\end{array}$} & 4 & $895,58 \mathrm{a}$ & $252,74 \mathrm{a}$ & 511,33 a & $1049,53 \mathrm{a}$ \\
\hline & 12 & 887,99 a & $209,31 \mathrm{a}$ & $470,43 \mathrm{a}$ & $1190,92 \mathrm{a}$ \\
\hline & Média & 891,79 B & $231,52 \mathrm{D}$ & $490,88 \mathrm{C}$ & $1158,35 \mathrm{~A}$ \\
\hline & & CV - 22,48\% & $48 \%$ & & \\
\hline \multirow{3}{*}{$\begin{array}{c}\text { Mg } \\
\left(\text { mg planta }^{-1}\right)\end{array}$} & 4 & 96,68 a & $41,54 \mathrm{a}$ & $94,91 \mathrm{a}$ & $156,65 \mathrm{a}$ \\
\hline & 12 & $116,56 \mathrm{a}$ & 39,32 a & $86,28 \mathrm{a}$ & $194,06 \mathrm{a}$ \\
\hline & Média & $106,32 \mathrm{~B}$ & $40,43 \mathrm{C}$ & $90,60 \mathrm{~B}$ & $194,62 \mathrm{~A}$ \\
\hline \multicolumn{6}{|c|}{ CV $-53,94 \%$} \\
\hline \multirow{4}{*}{$\begin{array}{c}\mathrm{Na} \\
\left(\mathrm{mg} \mathrm{planta}^{-1}\right)\end{array}$} & 4 & $2,16 \mathrm{a}$ & $1,45 \mathrm{a}$ & $1,88 \mathrm{a}$ & $2,87 \mathrm{~b}$ \\
\hline & 12 & $2,24 \mathrm{a}$ & $1,11 \mathrm{a}$ & $2,14 \mathrm{a}$ & $4,36 \mathrm{a}$ \\
\hline & Média & $2,20 \mathrm{~B}$ & $1,28 \mathrm{C}$ & $2,01 \mathrm{~B}$ & $3,74 \mathrm{~A}$ \\
\hline & & \multicolumn{2}{|c|}{ CV - 28,09\% } & & \\
\hline \multirow{3}{*}{$\begin{array}{c}\text { K } \\
\left(\mathrm{mg} \mathrm{planta}^{-1}\right)\end{array}$} & 4 & 8,35 a & $4,48 \mathrm{a}$ & $6,66 \mathrm{a}$ & $11,90 \mathrm{~b}$ \\
\hline & 12 & $7,75 \mathrm{a}$ & $3,51 \mathrm{~b}$ & $6,77 \mathrm{a}$ & $14,56 \mathrm{a}$ \\
\hline & Média & 8,05 B & $3,99 \mathrm{D}$ & $6,72 \mathrm{C}$ & $13,58 \mathrm{~A}$ \\
\hline \multicolumn{6}{|c|}{ CV $-21,25 \%$} \\
\hline \multirow{4}{*}{$\begin{array}{c}\mathrm{Cl} \\
\left(\mathrm{mg} \text { planta }^{-1}\right)\end{array}$} & 4 & $353,87 \mathrm{a}$ & $179,88 \mathrm{a}$ & $284,23 \mathrm{a}$ & $531,01 \mathrm{a}$ \\
\hline & 12 & $351,95 \mathrm{a}$ & $144,02 \mathrm{a}$ & 261,39 a & $603,79 \mathrm{a}$ \\
\hline & Média & $352,91 \mathrm{~B}$ & $161,95 \mathrm{D}$ & $272,81 \mathrm{C}$ & $588,02 \mathrm{~A}$ \\
\hline & \multicolumn{5}{|c|}{ CV $-18,63 \%$} \\
\hline
\end{tabular}

${ }^{1}$ Médias seguidas de mesma letra minúscula nas colunas e maiúscula nas linhas, não diferem estatisticamente pelo teste de Tukey a $5 \%$ de probabilidade, dentro de cada solo de irrigação aos 15 dias, decrescendo daí até os 45 dias, estabilizando-se após este período. O aumento da salinidade também provocou aumento na fitomassa seca da parte aérea até os 15 dias, com decréscimo até os 45 dias, seguido de estabilidade até o final do ciclo. Quanto à fitomassa seca total, foi notório o acréscimo aos 15 dias, com posterior estabilidade.

Observaram-se produções de matéria fresca e seca diferenciadas entre as plantas cultivadas nos quatro solos, na seqüência Neossolo > Cambissolo > Latossolo > Argissolo, coincidindo com a ordem de acúmulo dos elementos avaliados (Tabela 3) e, curiosamente, na ordem inversa da macroporosidade (Tabela 1). As plantas cultivadas no Neossolo produziram 2,97 vezes mais matéria fresca e 3,30 vezes mais matéria seca que aquelas no Argissolo, menos produtivas; o Neossolo, apesar de conter maior teor de $\mathrm{Na}^{+}$que os demais solos (Tabela 2), além de receber esse elemento nas soluções aplicadas, também é o solo que apresenta teores mais elevados de $\mathrm{Ca}$, Mg e K, elementos essenciais, enquanto o Argissolo é o solo mais pobre nesses nutrientes (Tabela 2), refletindo nos conteúdos acumulados dos mesmos nas plantas de meloeiro (Tabela 3). A seqüência de produção entre os solos coincidiu com a de acúmulo dos elementos nas plantas e com os teores desses últimos nos solos ao original, parecendo indicar que solos mais ricos em $\mathrm{Ca}, \mathrm{Mg}$ e $\mathrm{K}$ podem manter o fornecimento desses nutrientes às plantas, mesmo com acréscimos de $\mathrm{Na}$ ao sistema.

Os conteúdos de $\mathrm{Cl}$ nas plantas se encontram com valores superiores aos de $\mathrm{Mg}$ e $\mathrm{K}$, apesar deste ser um micronutriente; isto ocorre em conseqüência da composição da solução, à base de cloretos de $\mathrm{Na}$ e $\mathrm{Ca}$, proporcionando grandes acúmulos deste elemento. Esses elevados conteúdos acumulados de $\mathrm{Cl}$ devem ter contribuído para os decréscimos de produção observados.

Apesar das soluções de RAS 12 serem constituídas, proporcionalmente, de maiores teores de $\mathrm{Na}$ em relação ao Ca, não se observou influência da RAS nos conteúdos acumulados de $\mathrm{Na}$ e Ca pelas plantas de meloeiro. É possível que a diferença entre os valores de RAS adotados não tenha sido suficiente para promover alterações na absorção dos mesmos, inibindo-as ou estimulando.

Para observar o comportamento dos dados de produção e de conteúdos acumulados de $\mathrm{Ca}, \mathrm{Mg}, \mathrm{Na}, \mathrm{K}$ e $\mathrm{Cl}$ em relação à salinidade das soluções aplicadas, ajustaram-se modelos de regressão para cada solo. As equações selecionadas apresentaram parâmetros significativos, no mínimo a 10\% de probabilidade e com elevado coeficiente de determinação para todas as variáveis analisadas, comprovando a influência da CE da água usada na irrigação, tanto sobre a produção da planta quanto em relação ao acúmulo dos elementos pelo meloeiro. Com as equações ajustadas, elaboraram-se figuras para ilustrar o comportamento dessas variáveis nos quatro solos estudados (Figuras 1, 2, 3 e 4).

A produção de matéria fresca e matéria seca, foi reduzida com os incrementos da CE, pois todas as equações são decrescentes, com diferenças entre os solos em estudo (Figura 1). As plantas cultivadas no Argissolo Vermelho e no Latossolo Vermelho-Amarelo, apresentaram menores 

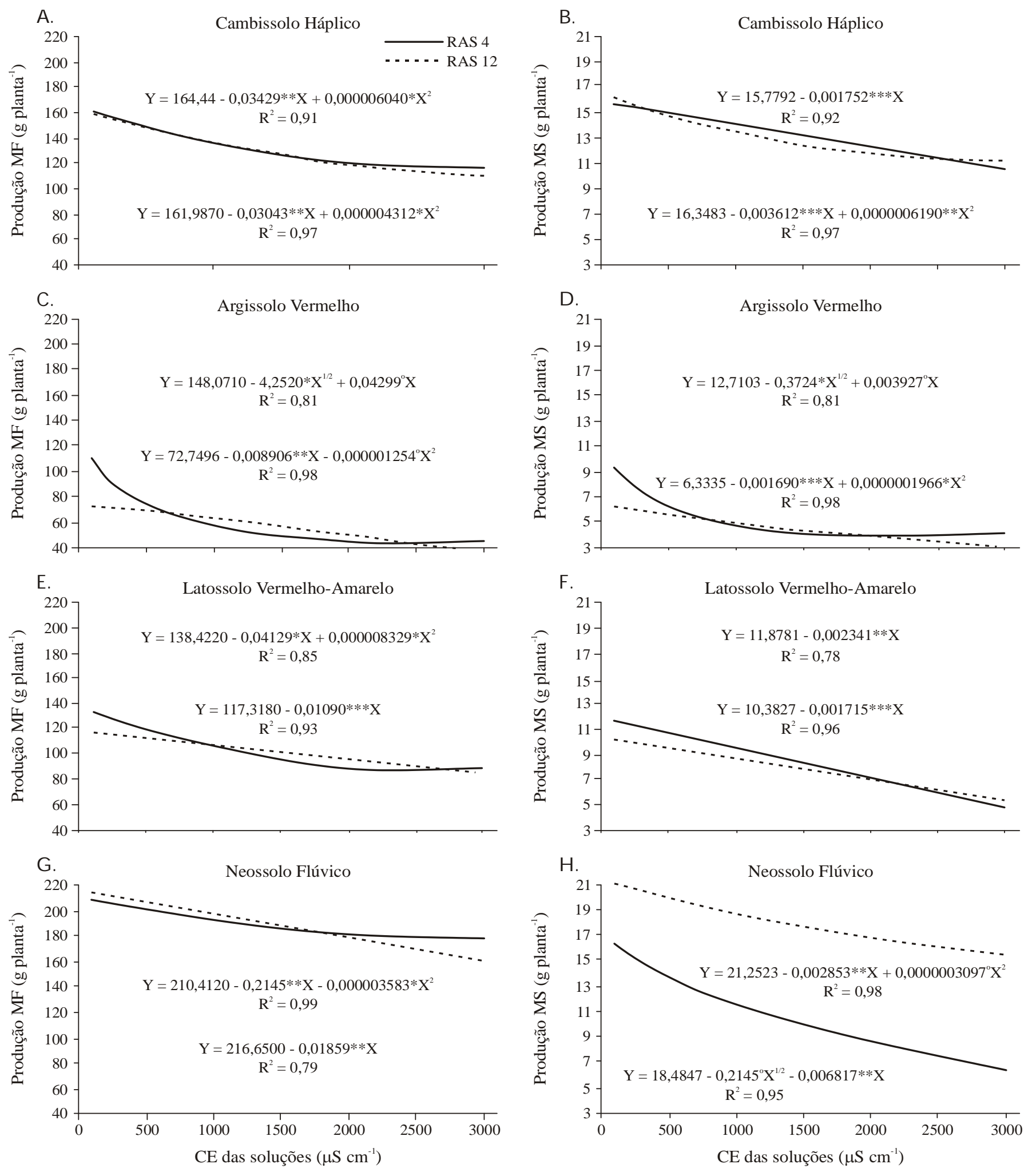

Figura 1. Equações de regressão da produção de matéria fresca (M F), matéria seca (M S) em função da condutividade elétrica e das RAS da solução de percolação no primeiro cultivo, para os quatro solos estudados.

produções de matéria fresca e seca, seguidas pelas do Cambissolo Háplico e, finalmente, as do Neossolo Flúvico, promovendo maiores produções.

No Argissolo, a produção de matéria fresca e seca foi mais afetada, atingindo valores mínimos a partir da $\mathrm{CE}=1.750 \mu \mathrm{S} \mathrm{cm}$, , na solução sendo esta classificada, ain- da, como C3, água muito utilizada na irrigação com meloeiro na região (Medeiros et al., 2003). Para os outros solos, esta mesma CE não afetou muito a produção da cultura, confirmando o que fôra observado sobre a diferenciação dos solos na capacidade de manutenção da cultura do meloeiro com águas salinas. 
As equações obtidas para os dois valores de RAS das soluções, estiveram sempre próximas, exceto para o Neossolo, no qual a RAS 4 proporcionou produção de matéria seca inferior a RAS 12, que pode ter ocorrido em função do alto teor de Ca neste solo (Tabela 2), que corresponde a uma ele-
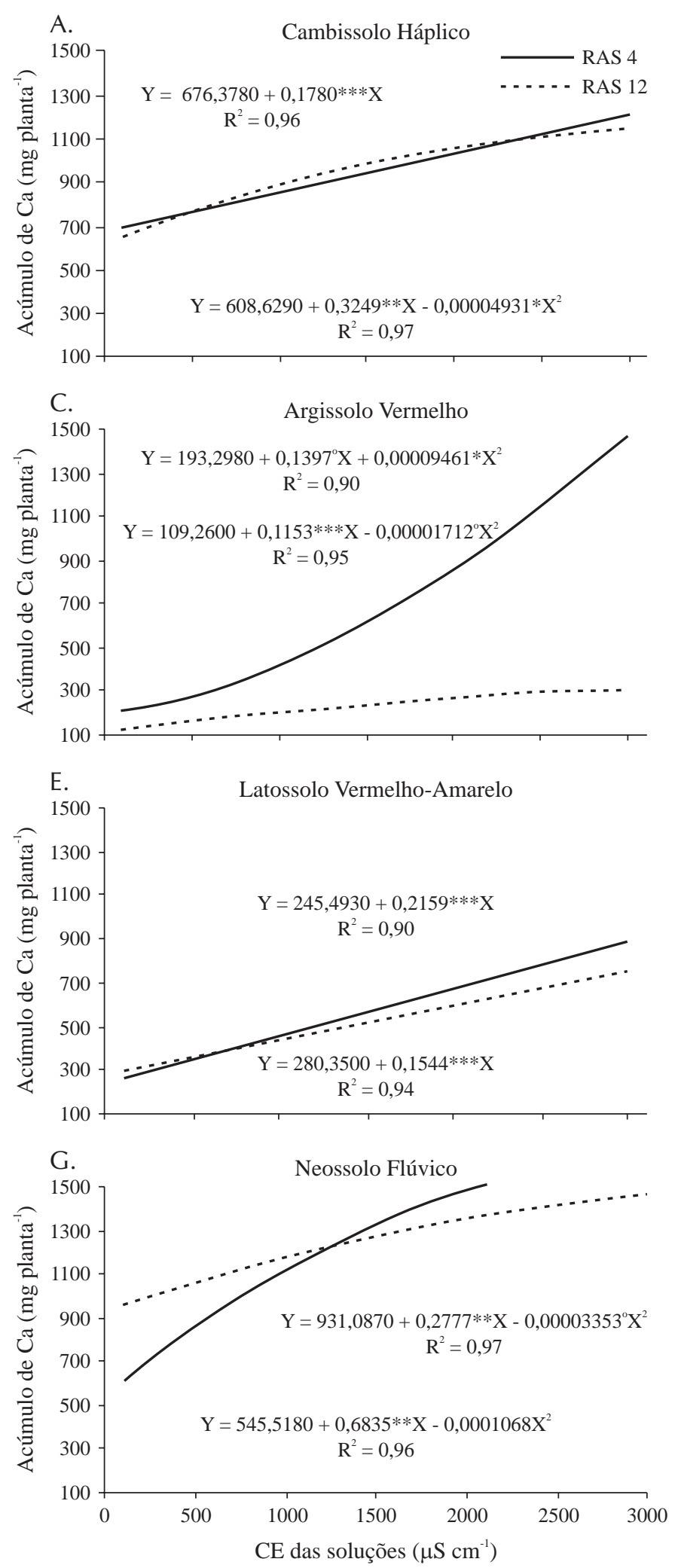

vada proporção deste elemento no complexo de troca do solo. Com o uso de uma solução mais rica em Ca, como é o caso da RAS 4, pode ter ocorrido dificuldade de absorção de $\mathrm{Mg}$ e K por competição entre os cátions.

Souza et al. (2003), considerando apenas os tratamentos
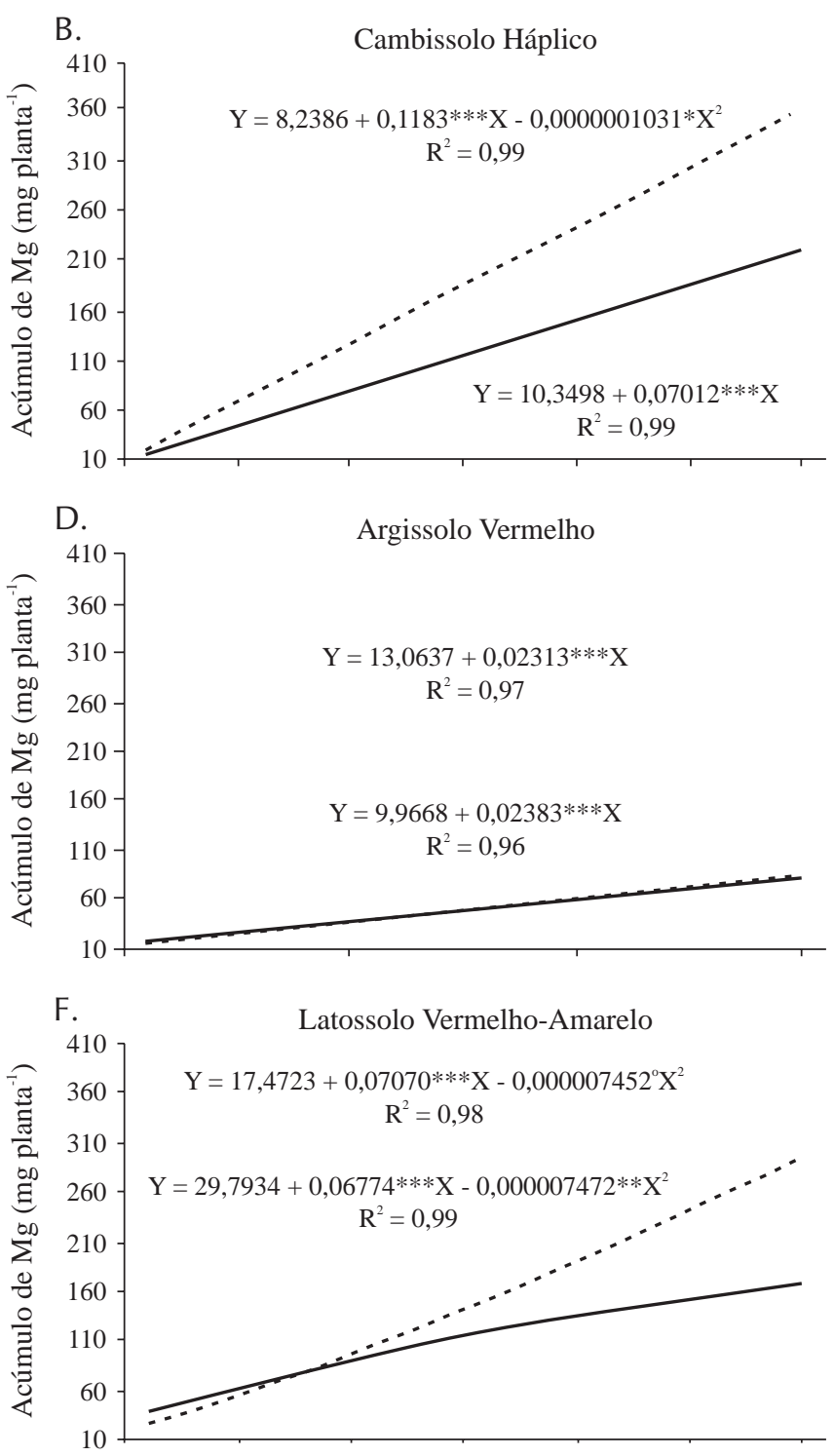

H. Neossolo Flúvico

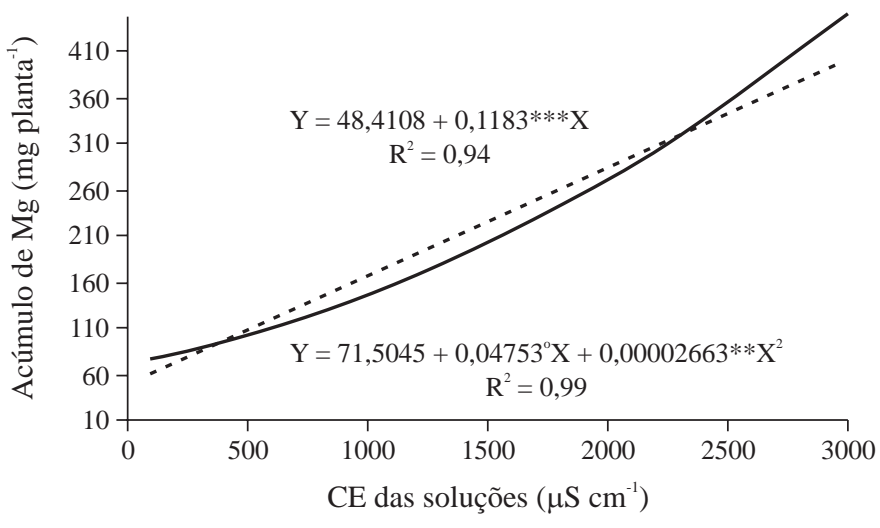

Figura 2. Equações de regressão dos conteúdos de Ca e Mg acumulados em função da condutividade elétrica e da RAS da solução de percolação no primeiro cultivo, para os quatro solos estudados 
A.

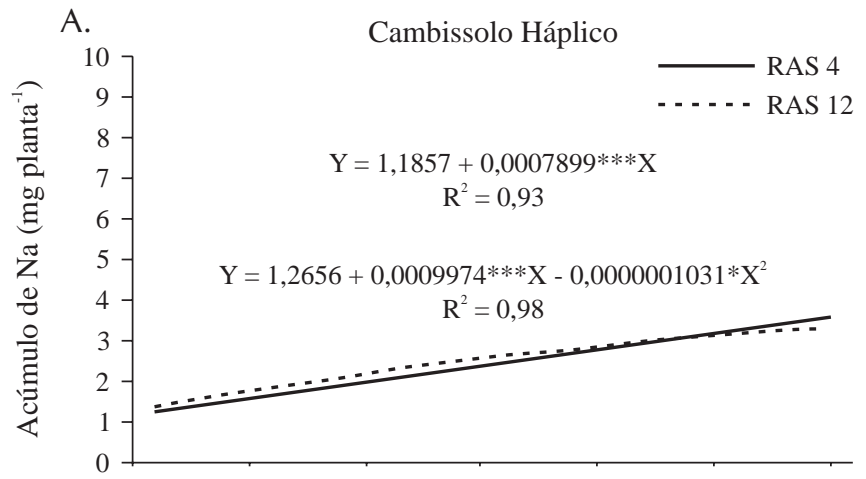

C.

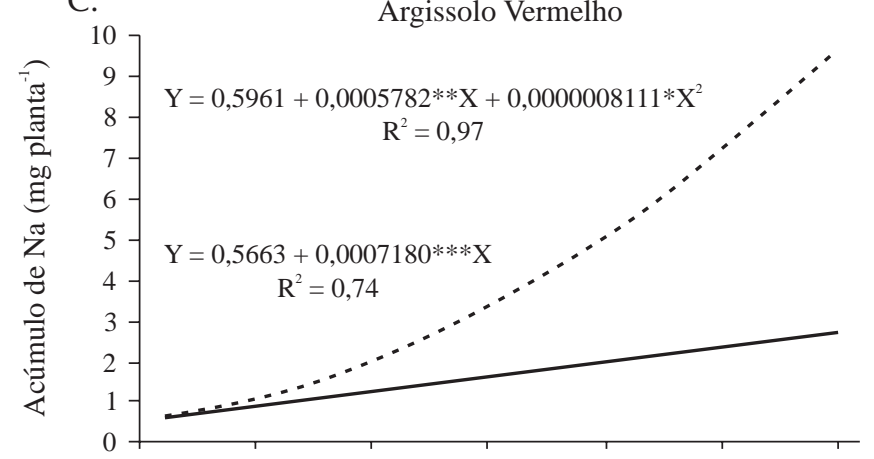

E.

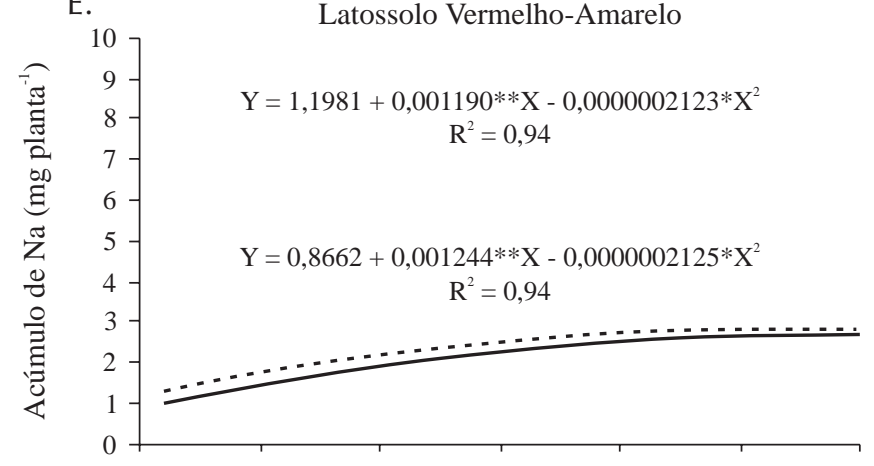

G.

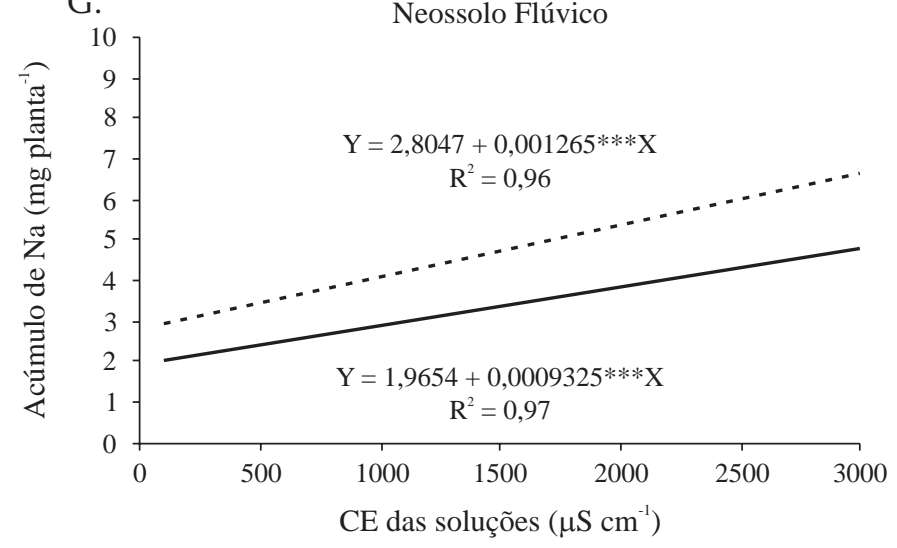

B.

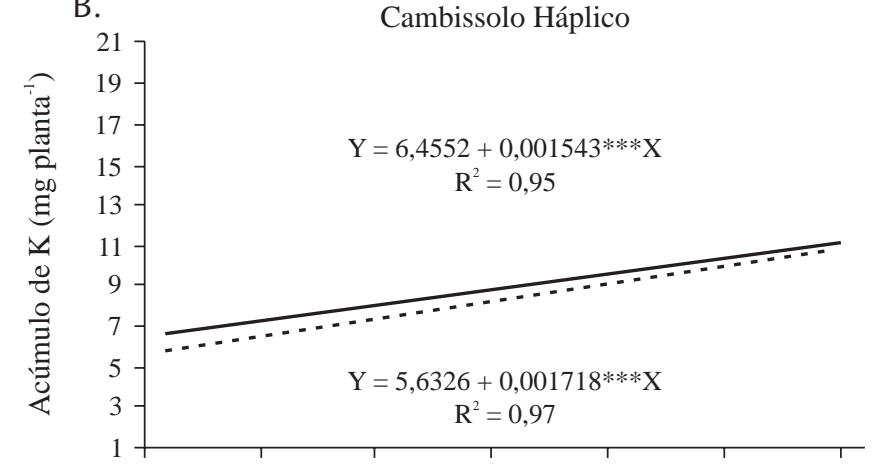

D.
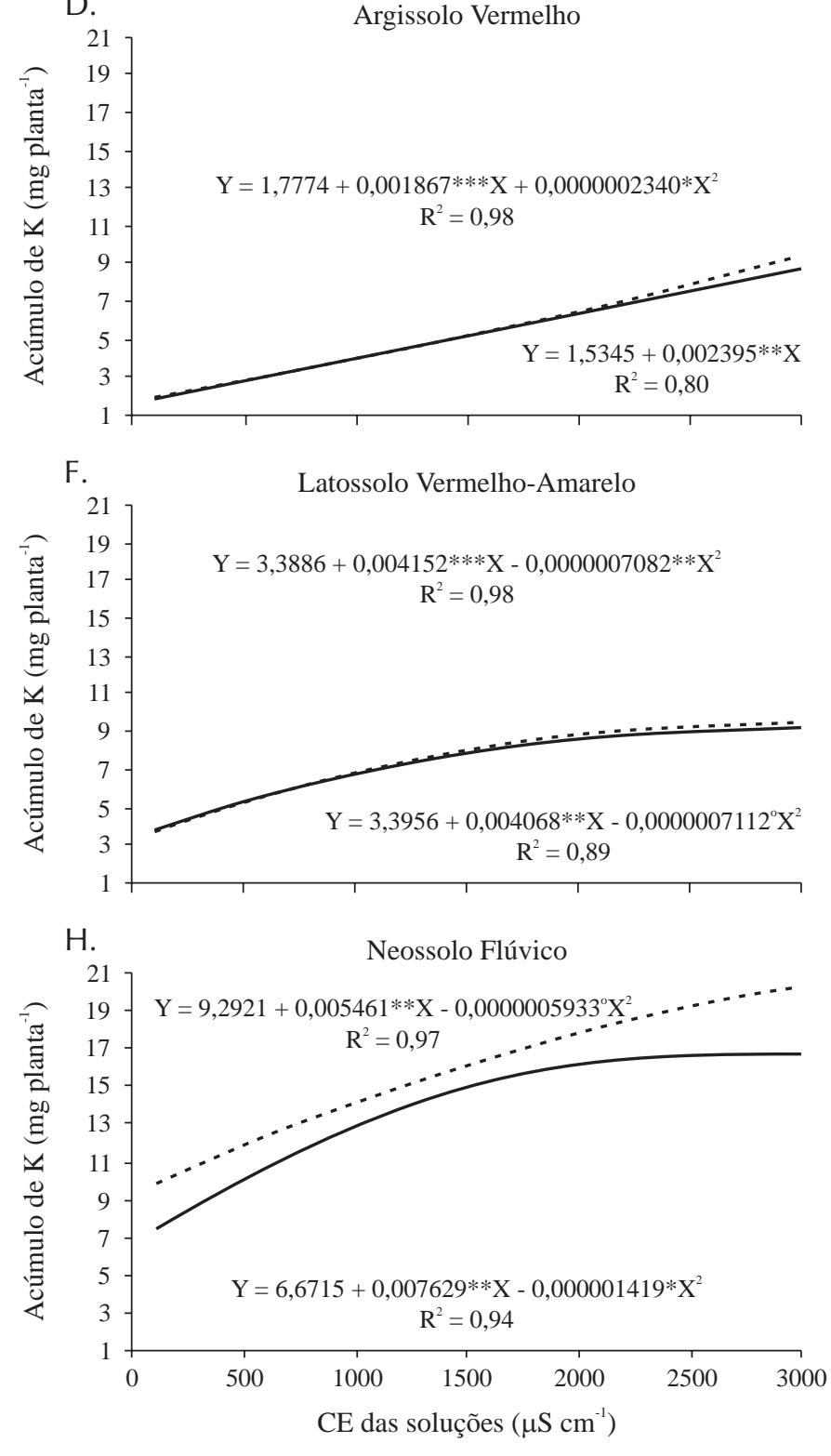

Figura 3. Equações de regressão dos conteúdos de $\mathrm{Na}$ e $\mathrm{K}$ acumulados em função da condutividade elétrica e da RAS da solução de percolação no primeiro cultivo, para os quatro solos estudados

nos quais a salinidade da água de irrigação foi mantida constante durante todo o ciclo da cultura, notaram perda na produção, de aproximadamente $10 \%$, por incremento de uma unidade na CE da água de irrigação.

O incremento nos conteúdos acumulados dos elementos ocorreu nos quatro solos, destacando-se os elevados valores de $\mathrm{Cl}$ na planta, inferiores apenas aos de Ca (Figuras 2, 3 e 4); este elemento já é encontrado naturalmente na solução do solo (Tabela 2), além de ter sido adicionado nas soluções de percolação, na forma de $\mathrm{NaCl}$ e $\mathrm{CaCl}_{2}$. 

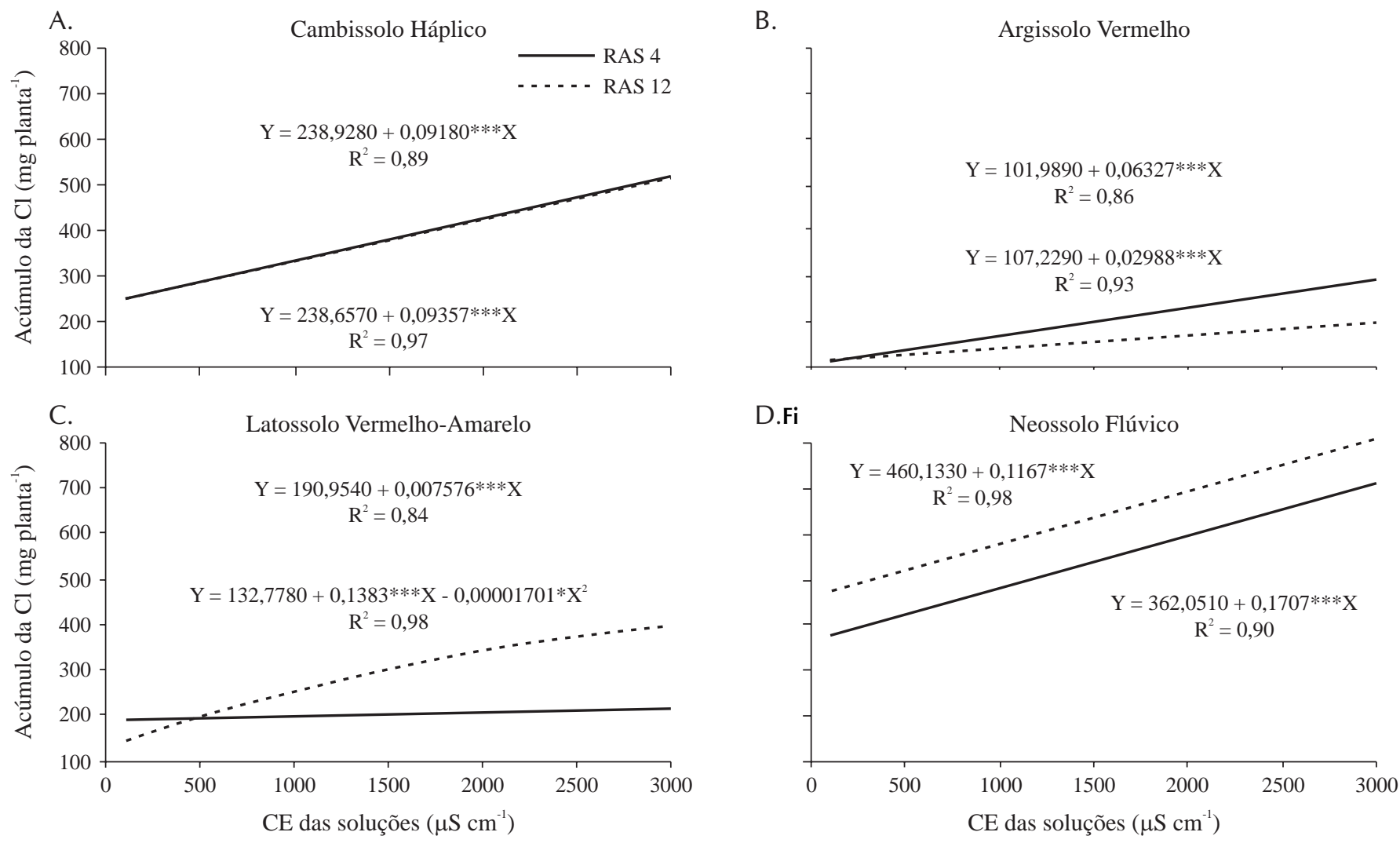

Figura 4. Produção(1) de matéria fresca (MF), matéria seca (MS) e conteúdos de $\mathrm{Ca}, \mathrm{Mg}, \mathrm{Na}, \mathrm{K}$ e $\mathrm{Cl}$ no segundo cultivo de plantas de meloeiro irrigados com águas de salinidade variável para os quatro solos estudados

Tabela 4. Produção(1) de matéria fresca (MF), matéria seca (MS) e conteúdos de $\mathrm{Ca}, \mathrm{Mg}$, $\mathrm{Na}, \mathrm{K} \mathrm{e} \mathrm{Cl}$ no segundo cultivo de plantas de meloeiro irrigados com águas de salinidade variável para os quatro solos estudados

\begin{tabular}{|c|c|c|c|c|c|}
\hline \multirow{2}{*}{ Variável } & \multirow{2}{*}{ RAS } & \multicolumn{4}{|c|}{ Solo } \\
\hline & & CXve & PVd & LVAe & RYve \\
\hline \multirow{3}{*}{$\begin{array}{c}\text { MS } \\
\left(\text { g planta }^{-1}\right)\end{array}$} & 4 & $0,86 \mathrm{a}$ & $0,37 \mathrm{a}$ & $0,33 \mathrm{a}$ & $0,50 \mathrm{a}$ \\
\hline & 12 & $0,80 \mathrm{a}$ & $0,31 \mathrm{a}$ & $0,33 \mathrm{a}$ & $0,39 \mathrm{a}$ \\
\hline & Média & $0,83 \mathrm{~A}$ & $0,34 \mathrm{BC}$ & $0,33 \mathrm{C}$ & $0,44 \mathrm{~B}$ \\
\hline \multicolumn{6}{|c|}{ CV $-41,93 \%$} \\
\hline \multirow{3}{*}{$\begin{array}{c}\mathrm{Ca} \\
\left(\mathrm{mg} \mathrm{planta}^{-1}\right)\end{array}$} & 4 & $32,16 \mathrm{a}$ & 26,34 a & $32,15 \mathrm{a}$ & $28,61 \mathrm{a}$ \\
\hline & 12 & $29,75 \mathrm{a}$ & $24,61 \mathrm{a}$ & $32,34 \mathrm{a}$ & $21,88 \mathrm{a}$ \\
\hline & Média & $30,96 \mathrm{AB}$ & $25,48 \mathrm{~B}$ & $32,25 \mathrm{~A}$ & $25,24 \mathrm{~B}$ \\
\hline \multicolumn{6}{|c|}{ CV $-42,24 \%$} \\
\hline \multirow{3}{*}{$\begin{array}{c}M g \\
\left(\mathrm{mg} \mathrm{planta}^{-1}\right)\end{array}$} & 4 & $6,41 \mathrm{a}$ & $2,64 \mathrm{a}$ & $2,91 \mathrm{a}$ & $2,83 \mathrm{a}$ \\
\hline & 12 & $5,45 \mathrm{a}$ & $1,73 \mathrm{a}$ & $2,42 \mathrm{a}$ & $2,73 \mathrm{a}$ \\
\hline & Média & $5,93 \mathrm{~A}$ & $2,19 \mathrm{~B}$ & $2,67 \mathrm{~B}$ & $2,78 \mathrm{~B}$ \\
\hline \multicolumn{6}{|c|}{ CV - $64,35 \%$} \\
\hline \multirow{3}{*}{$\begin{array}{c}\mathrm{Na} \\
\left(\mathrm{mg} \mathrm{planta}^{-1}\right)\end{array}$} & 4 & $2,86 \mathrm{a}$ & $2,72 \mathrm{a}$ & $2,51 \mathrm{a}$ & $3,09 \mathrm{a}$ \\
\hline & 12 & $2,57 \mathrm{a}$ & $2,57 \mathrm{a}$ & $2,27 \mathrm{a}$ & $2,57 \mathrm{~b}$ \\
\hline & Média & $2,72 \mathrm{~A}$ & $2,65 \mathrm{~A}$ & $2,39 \mathrm{~A}$ & $2,83 \mathrm{~A}$ \\
\hline \multicolumn{6}{|c|}{ CV $-33,81 \%$} \\
\hline \multirow{3}{*}{$\begin{array}{c}\mathrm{K} \\
\left(\mathrm{mg} \text { planta }^{-1}\right)\end{array}$} & 4 & $0,37 \mathrm{a}$ & $0,50 \mathrm{a}$ & $0,56 \mathrm{a}$ & $0,45 \mathrm{a}$ \\
\hline & 12 & $0,46 \mathrm{a}$ & $0,57 \mathrm{a}$ & $0,49 a$ & $0,54 \mathrm{a}$ \\
\hline & Média & $0,41 \mathrm{~B}$ & $0,53 \mathrm{~A}$ & $0,53 \mathrm{~A}$ & $0,50 \mathrm{AB}$ \\
\hline \multicolumn{6}{|c|}{ CV $-33,19 \%$} \\
\hline \multirow{4}{*}{$\begin{array}{c}\mathrm{Cl} \\
\left(\mathrm{mg} \mathrm{planta}^{-1}\right)\end{array}$} & 4 & $78,85 \mathrm{a}$ & $43,15 \mathrm{a}$ & $39,36 \mathrm{a}$ & $49,28 \mathrm{a}$ \\
\hline & 12 & $75,13 \mathrm{a}$ & $36,76 \mathrm{a}$ & $39,52 \mathrm{a}$ & $47,28 \mathrm{~b}$ \\
\hline & Média & $78,43 \mathrm{~A}$ & $41,21 \mathrm{C}$ & $40,69 \mathrm{C}$ & $54,53 \mathrm{~B}$ \\
\hline & \multicolumn{5}{|c|}{ CV $-44.23 \%$} \\
\hline
\end{tabular}

${ }^{1}$ Médias seguidas de mesmas letras minúsculas nas colunas e maiúsculas nas linhas, não diferem estatisticamente pelo teste de Tukey a $5 \%$ de probabilidade, dentro de cada solo
No segundo cultivo de meloeiro também se deu decréscimo de produção de matéria seca e aumento na acumulação de $\mathrm{Ca}, \mathrm{Mg}$, Na, K e Cl (Tabela 4). Os sintomas de toxidez foram observados no início do ciclo da cultura, oito dias após o transplantio, evoluindo rapidamente e culminando com a morte das plantas. Os sais que permaneceram no solo fornecido pelas águas do primeiro ciclo, concentrando-se com a evaporação da água do solo no intervalo entre os dois ciclos, possivelmente contribuíram para este fato; quando as plantas do segundo ciclo foram transplantadas, não suportaram a elevada salinidade do solo por ainda se encontrarem em estado muito frágil, fato confirmado pelas baixas produções alcançadas que corresponderam, no máximo, a vinte dias de cultivo, com decréscimos em relação à elevação da CE das soluções aplicadas.

Observa-se ainda, que, do primeiro cultivo para o segundo, a redução da MS foi mais intensa com o incremento na salinidade da água de irrigação, comportamento este que pode ser atribuído à maior salinidade do solo com o tempo de cultivo reduzindo, com isto, o potencial osmótico da solução do solo, dificultando a absorção de água pelas plantas, o que promoveu diminuição no crescimento e produção do meloeiro com o incremento da concentração salina, concordando com Meiri et al. (1982). Alencar et al. (2003) observaram que as reduções na fitomassa fresca foram superiores a $16 \%$ por aumento unitário da condutividade elétrica, enquanto a fitomassa seca da parte aérea foi reduzida em 15,5\%.

Da mesma forma que no primeiro cultivo, em geral não se observou influência da RAS da solução de percolação sobre 
a produção de matéria seca e os conteúdos acumulados; contudo, entre os solos, os resultados se inverteram, sendo o Cambissolo o que promoveu maiores produções de matéria seca das plantas de meloeiro, com maiores acúmulos de Ca (semelhante ao Latossolo), Mg e Cl. Para o Na na planta não se observaram diferenças entre os solos estudados.

Para todos os fatores em estudo para planta, equações de regressão foram ajustadas em função das CEs, para melhor explicar esses comportamentos e estimar uma formulação de águas que melhor se adaptem às condições, sem que haja perda na produção (Figuras 5, 6, 7 e 8).

Os problemas de morte das plantas influenciaram, também, os elevados valores do coeficiente de variação verificados (Tabelas 4), que superaram os do primeiro cultivo (Tabela 3).

Da mesma forma que ocorreu para o primeiro cultivo, a produção de matéria seca foi reduzida com os acréscimos na salinidade das soluções de percolação, enquanto os conteúdos acumulados de $\mathrm{Ca}, \mathrm{Mg}, \mathrm{Na}, \mathrm{K}$ e $\mathrm{Cl}$ aumentaram; porém, o $\mathrm{Cl}$ acumulado nas plantas foi superior a todos os outros elementos, podendo indicar forte efeito tóxico que promoveu a morte das plantas poucos dias após o transplantio (Figura 8). Os conteúdos de $\mathrm{Cl}$ superaram até mesmo os de Ca devido, provavelmente, à composição das águas de percolação. Deve ter ocorrido uma toxidez pelo Cl, já que este elemento é um micronutriente, podendo ter efeito tóxico às plantas em elevadas concentrações.

Neste segundo cultivo, as plantas cultivadas no Neossolo Flúvico apresentaram decréscimo mais acentuado na produção de matéria seca com o aumento da CE das soluções que
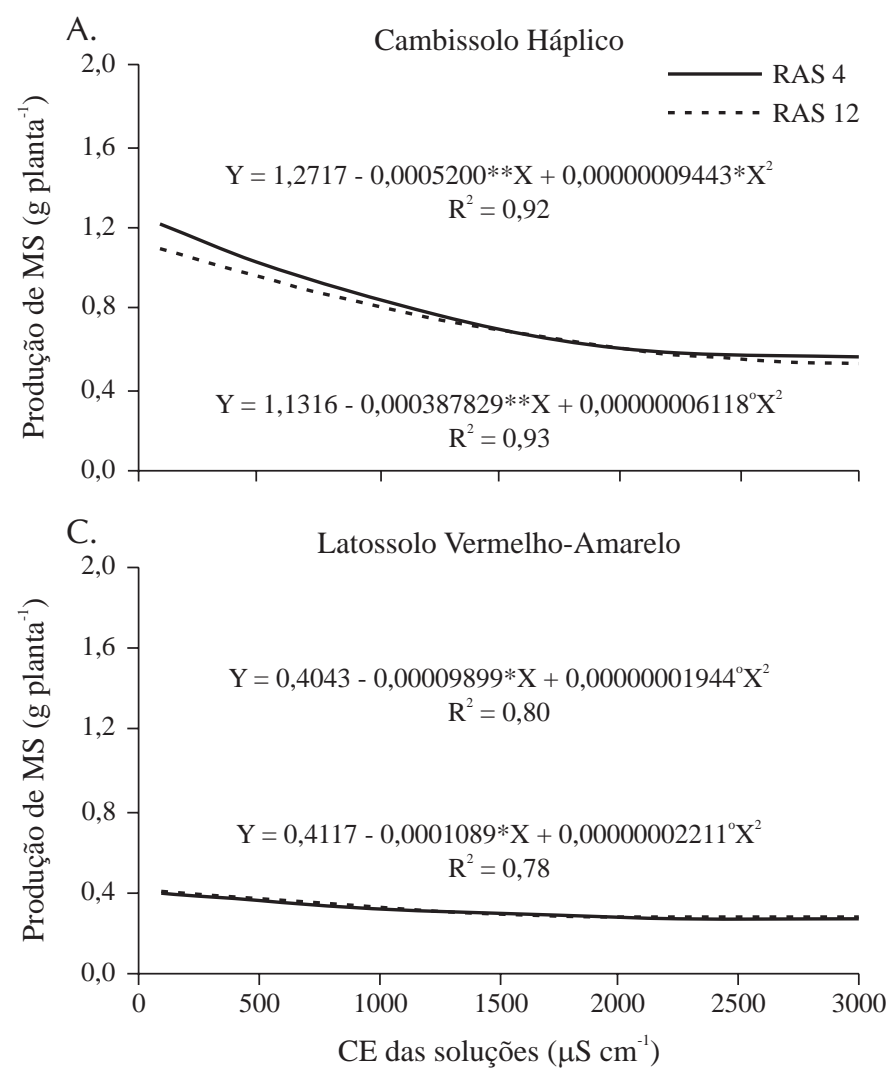

no primeiro cultivo. Freire et al. (2003a), trabalhando com solos de Pernambuco, constataram que um Neossolo Flúvico foi um dos solos mais afetados pela salinidade da água de percolação, com alterações consideráveis nas suas propriedades físicas; este solo já apresentava pequena macroporosidade associada à aeração e à drenagem. No presente estudo, a dificuldade de movimentação de ar e água neste solo também pode ter contribuído para a queda de produção e morte das plantas nele cultivadas, demonstrando que os solos reagem de maneira diferenciada aos tratamentos de salinidade da água de irrigação, sendo necessário um conhecimento das suas propriedades físicas e químicas, antes do uso de águas salinas e também o monitoramento, com o tempo de cultivo, para evitar problemas de queda de produção e desbalanços nutricionais promovidos pelos sais presentes na água.

Além disso, entre ciclos consecutivos deve-se manter a umidade elevada ou, mesmo, proporcionar uma lixiviação para evitar acúmulos excessivos de sais no solo, que dificultaria o cultivo das plantas, fato que não ocorreu neste estudo. Conforme já relatado, os solos ficaram sem receber irrigação no intervalo entre os dois cultivos elevando, sobremaneira, a salinidade dos solos, pela evaporação da água e manutenção dos sais nos solos.

Entre os quatro solos, o Cambissolo Háplico e o Neossolo Flúvico foram os que apresentaram maiores quedas de produção das plantas, nesse segundo cultivo; são os solos com maiores teores de argila de atividade alta, mais susceptíveis aos processos de salinização e sodificação (Freire et al., 2003b). Dentre os dois, o Neossolo Flúvico parece ser o mais

B.

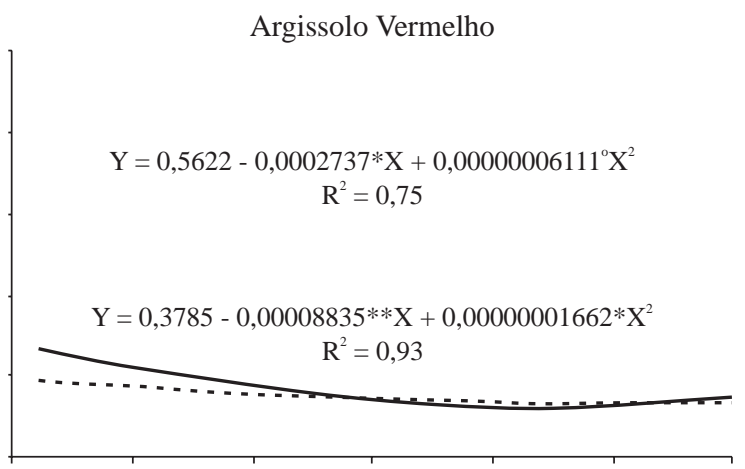

D.

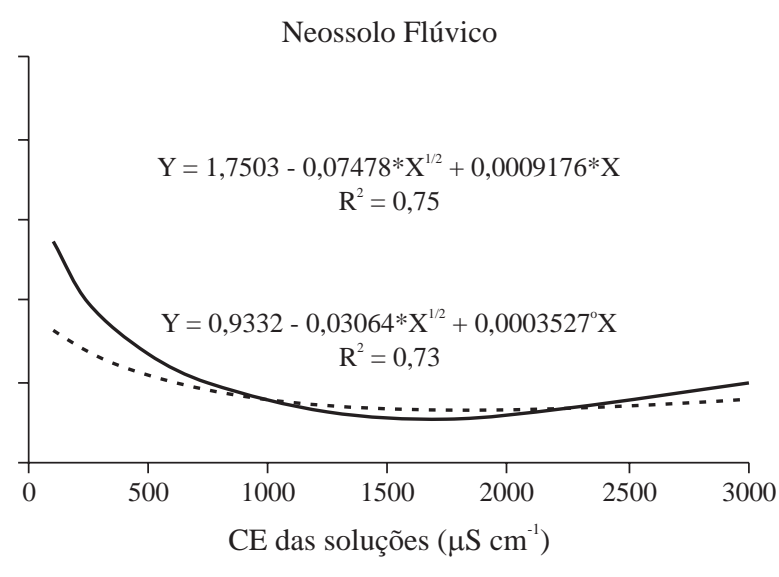

Figura 5. Equações de regressão da produção de matéria seca (MS) em função da condutividade elétrica da solução de percolação no segundo cultivo, para os quatro solos estudados 
A.

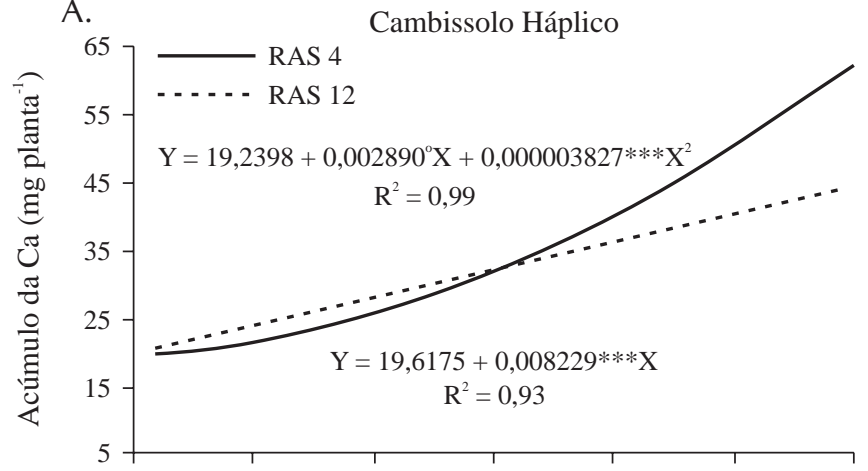

C.
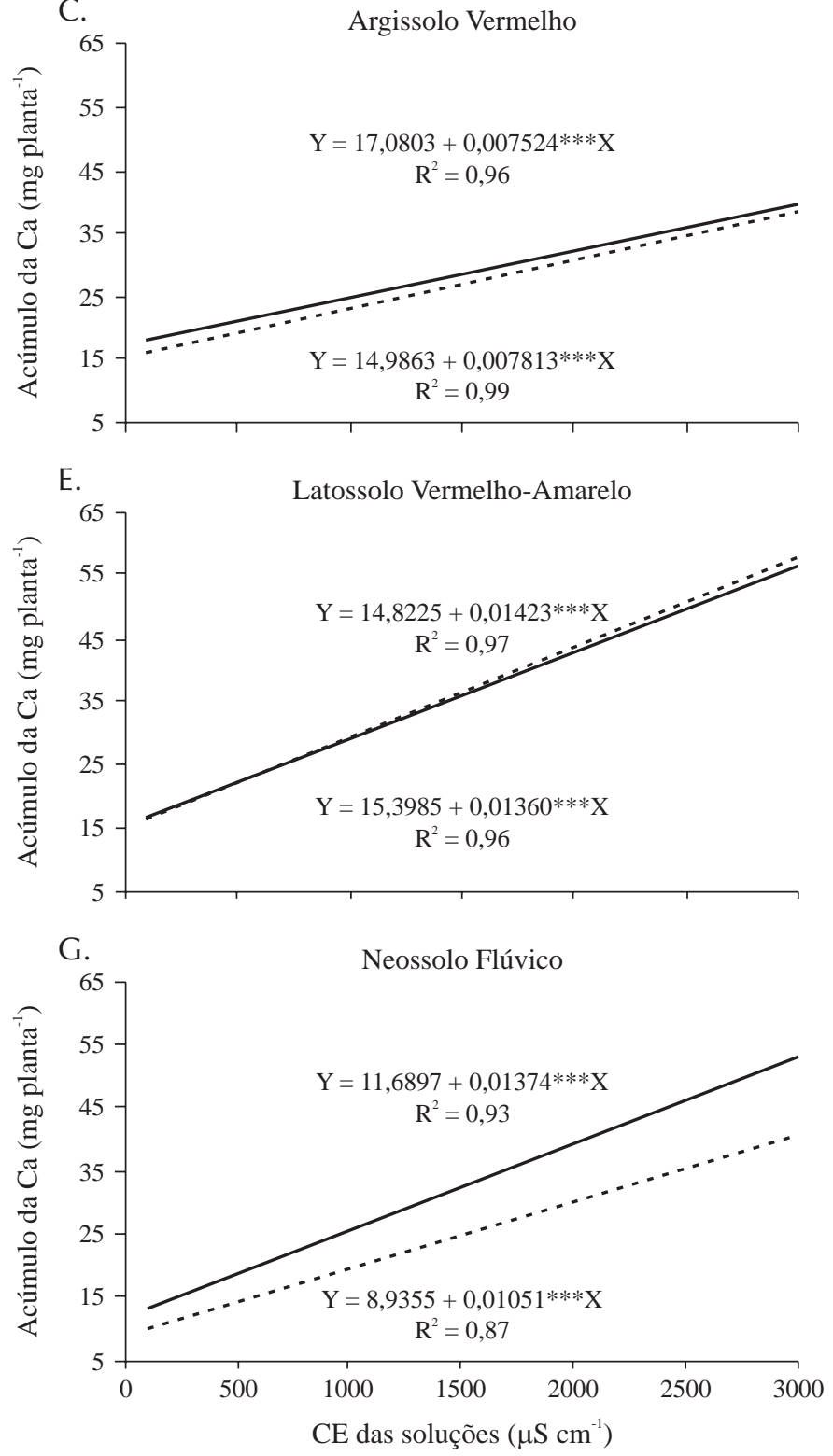

B.

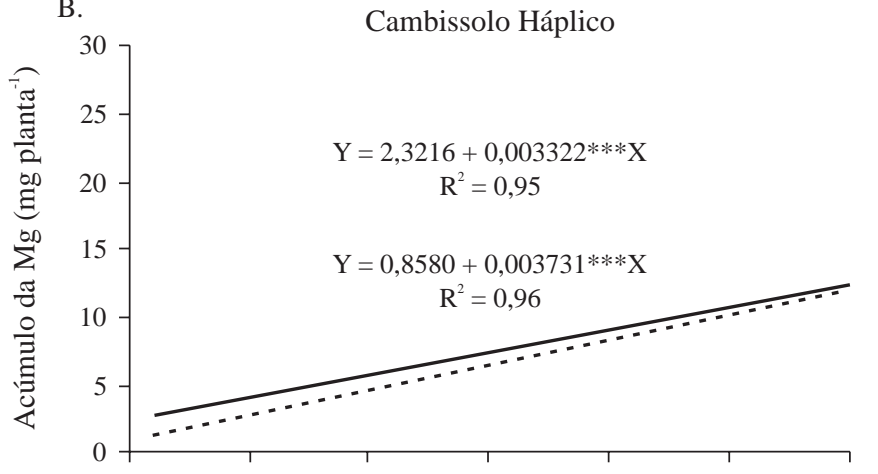

D.

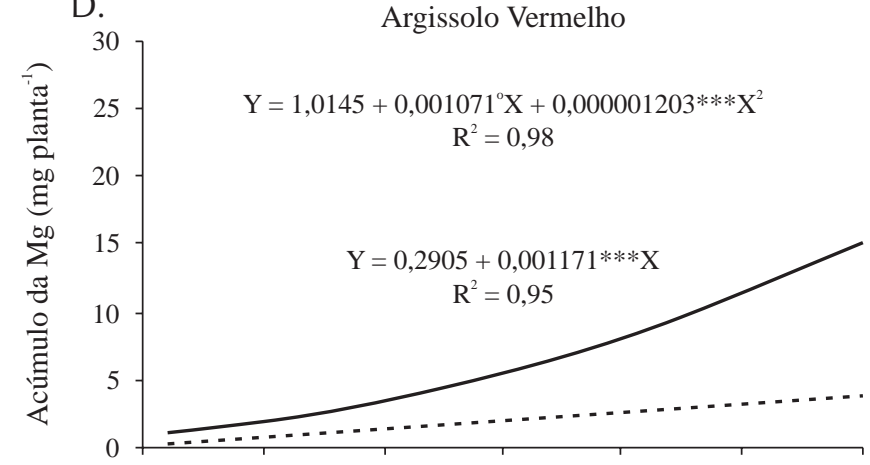

F.

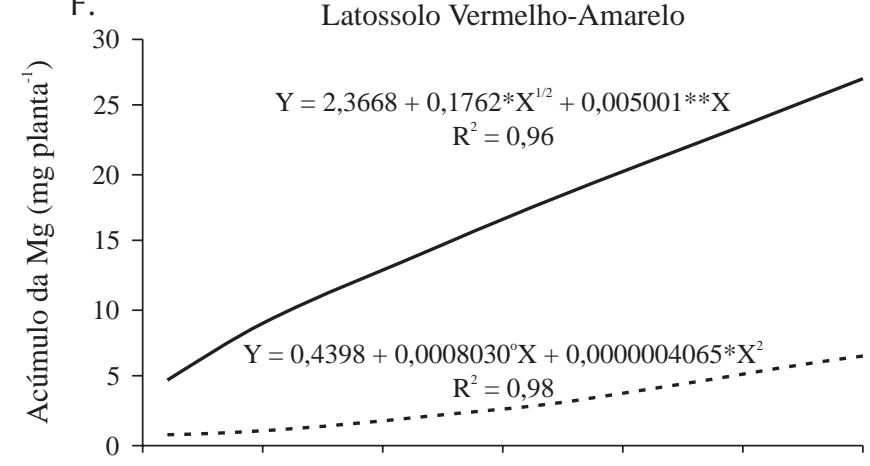

$\mathrm{H}$.

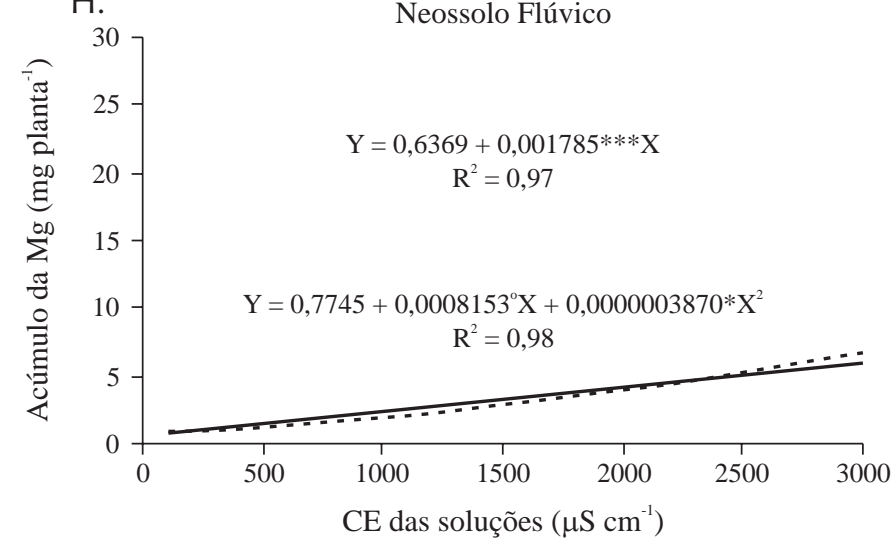

Figura 6. Equações de regressão dos conteúdos de Ca e Mg acumulados em função da condutividade elétrica e da RAS da solução de percolação no segundo cultivo, para os quatro solos estudados

propenso a esses processos em virtude da sua composição mineralógica, além da contribuição do silte, fração intermediária dos solos, que contribui para a obstrução de poros, reduzindo a condutividade hidráulica dos solos afetados por sais (Freire et al., 2003a).
Da mesma maneira verificada para o primeiro cultivo do meloeiro, os conteúdos acumulados de Ca e Mg também aumentaram com a elevação da CE das soluções aplicadas, tanto na RAS 4 quanto na 12 (Figura 6), o que também se notou para o Na e o K (Figura 7). As plantas irrigadas com 
soluções mais salinas acumularam mais esses elementos nos tecidos, provavelmente para possibilitar a absorção de água, mas os conteúdos parecem ter sido suficientemente elevados para promover as quedas de produção verificadas (Figura 5), e a morte das plantas, relatada anteriormente.
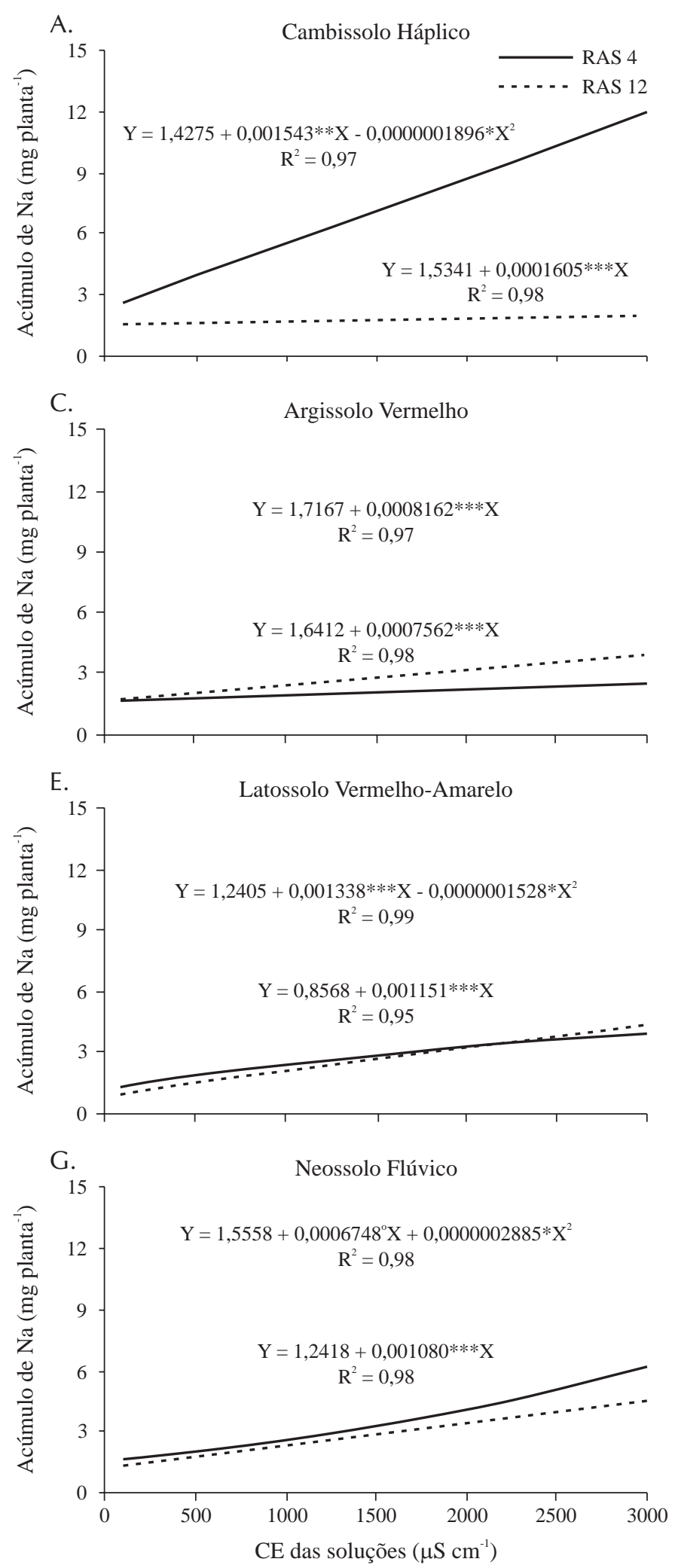

Outro fato que deve ter contribuído para a queda de produção e morte das plantas, é a elevação nos conteúdos de Cl acumulados com o aumento da CE das soluções de percolação, pois seus valores superam os dos outros elementos (Tabela 4), podendo ter ocorrido toxidez por $\mathrm{Cl}$ nas plantas de meloeiro,
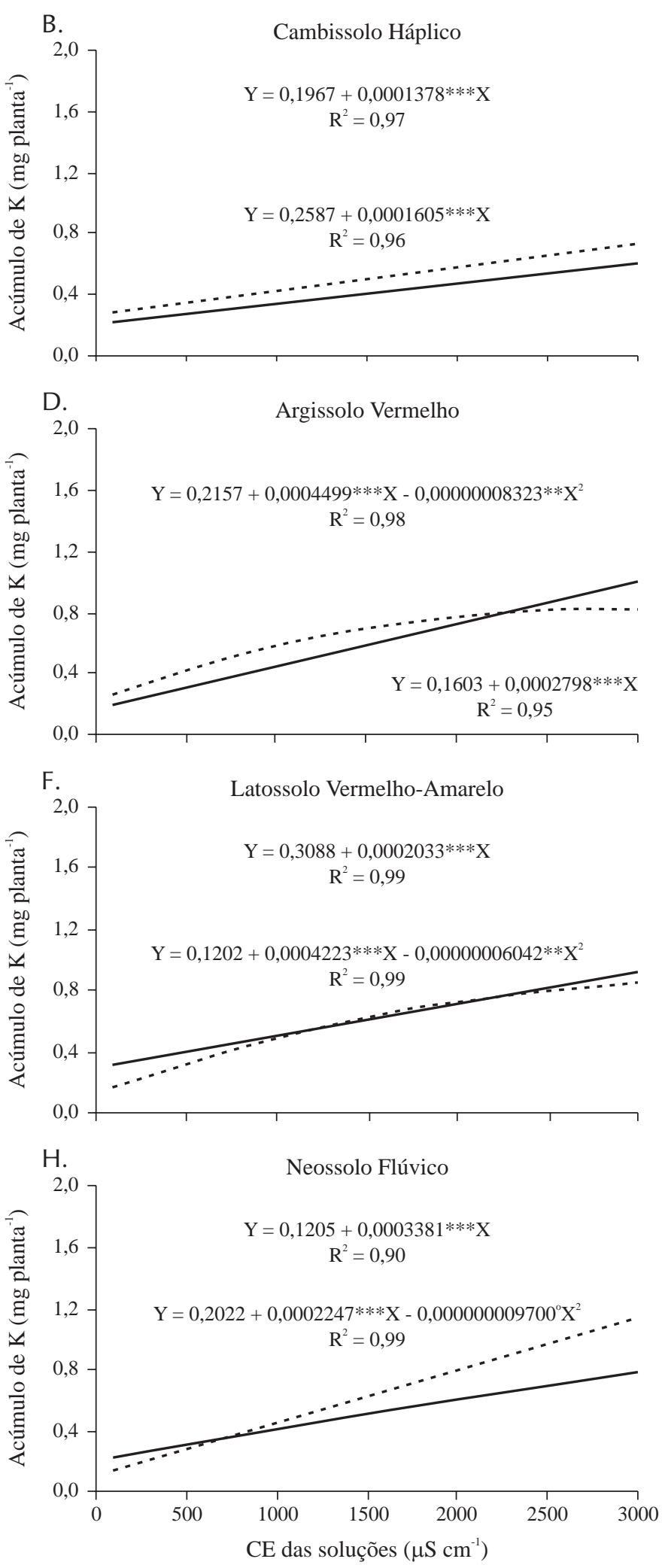

Figura 7. Equações de regressão dos conteúdos de $\mathrm{Na}$ e K acumulados em função da condutividade elétrica e da RAS da solução de percolação no segundo cultivo, para os quatro solos estudados 


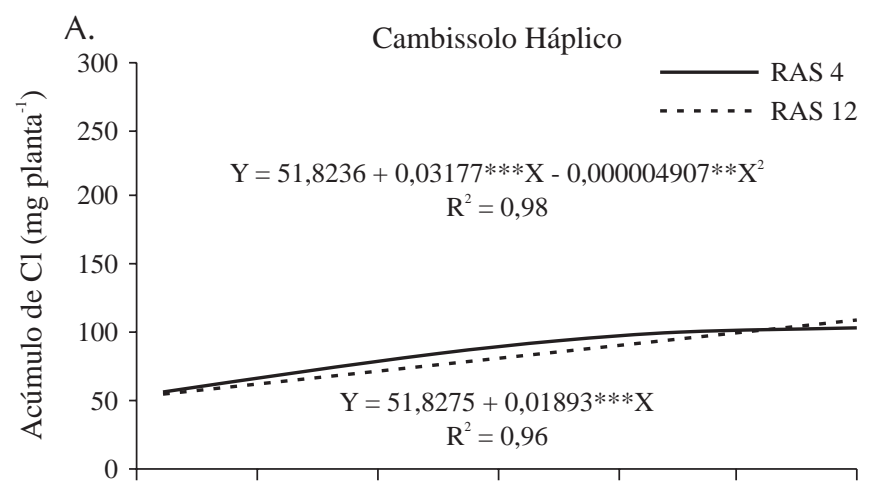

B.

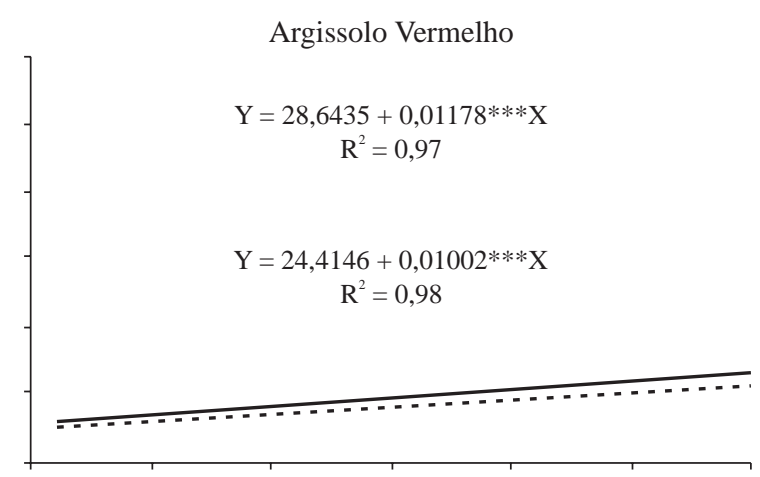

D.

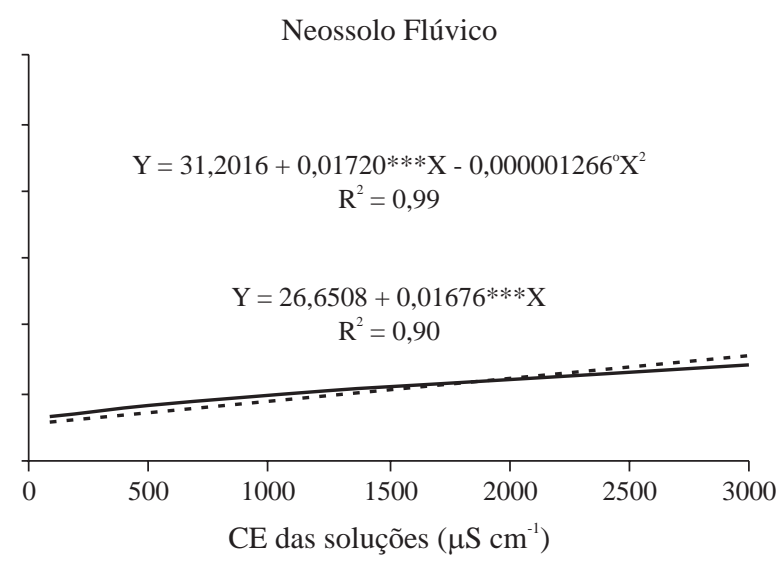

Figura 8. Equações de regressão do conteúdo de $\mathrm{Cl}$ acumulado em função da condutividade elétrica da solução de percolação no segundo cultivo, para os quatro solos estudados

demonstrando a importância do conhecimento da composição das águas usadas na irrigação, visto que seus íons poderão alterar o equilíbrio nutricional das culturas.

\section{CONCLUSÕES}

1. A produção das plantas de meloeiro e o acúmulo de Ca, $\mathrm{Mg}, \mathrm{Na}, \mathrm{K}$ e $\mathrm{Cl}$ dependem, de maneira diferenciada do tipo de solo, nos dois ciclos de cultivo.

2. A RAS de 4 e $12\left(\operatorname{mmol}_{C} L^{-1}\right)^{1 / 2}$, não interfere na produção do meloeiro nem no acúmulo de sais nas plantas, exceto em solo mais argiloso e com menos macroporosidade.

3. Há redução na produção de matéria fresca e seca e aumento no acúmulo de $\mathrm{Ca}^{2+}, \mathrm{Mg}^{2+}, \mathrm{Na}^{+}, \mathrm{K}^{+}$e $\mathrm{Cl}^{-}$nas plantas de meloeiro, nos dois ciclos de cultivo, quando irrigadas com soluções de condutividade elétrica crescente.

4. A salinidade dos solos proporciona a morte das plantas poucos dias após o transplantio do segundo cultivo, com elevados acúmulos de $\mathrm{Na}^{+}$e $\mathrm{Cl}^{-}$no tecido vegetal.

\section{LITERATURA CITADA}

Alencar, R. D.; Porto Filho, F. Q.; Medeiros, J. F. de; Holanda, J. S.; Porto, V. C.; Ferreira Neto, N. M. Crescimento de cultivares de melão amarelo irrigadas com água salina. Revista Brasileira de Engenharia Agrícola e Ambiental, v.7, n.2, p.221-226, 2003.
Bezerra Neto, E.; Barreto, L. P. Métodos de análises químicas em plantas. 1.ed. Recife: UFRPE, 2004. 165p.

Farias, C. H. A.; Espínola Sobrinho, J.; Medeiros, J. F. de; Costa, M. C.; Nascimento, I. B.; Silva, M. C. C. Crescimento e desenvolvimento da cultura do melão sob diferentes lâminas de irrigação e salinidade da água. Revista Brasileira de Engenharia Agrícola e Ambiental, v.7, n.3, p.445-450, 2003.

Freire, M. B. G. dos S.; Ruiz, H. A.; Ribeiro, M. R.; Ferreira, P. A.; Alvarez V. V. H.; Freire, F. J. Condutividade hidráulica de solos de Pernambuco em resposta à condutividade elétrica e RAS da água de irrigação. Revista Brasileira de Engenharia Agrícola e Ambiental, v.7, n.1, p.45-52, 2003a.

Freire, M. B. G. dos S.; Ruiz, H. A.; Ribeiro, M. R.; Ferreira, P. A.; Alvarez, V. V. H.; Freire, F. J. Estimativa do risco de sodificação de solos de Pernambuco pelo uso de águas salinas. Revista Brasileira de Engenharia Agrícola e Ambiental, v.7, n.2, p.227-232, 2003b.

Malavolta, E.; Vitti, G. C.; Oliveira, S. A. Avaliação do estado nutricional das plantas: Princípios e aplicações. Piracicaba: Associação Brasileira para Pesquisa da Potassa e do Fosfato, 1989. 201p.

Medeiros, J. F; Lisboa, R. A.; Oliveira, M.; Silva Júnior, M. J.; Alves, L. P. Caracterização das águas subterrâneas usadas para irrigação na área produtora de melão da Chapada do Apodi. Revista Brasileira de Engenharia Agrícola e Ambiental, v.7, n.3, p.469-472, 2003.

Meiri, A.; Hoffman, G.; Shannon, M.; Poss, J. Salt tolerance of two muskmelon cultivars under two solar radiation levels. Journal of the American Society for Horticultural Science, v.107, p.1168-72, 1982. 
Mendonça, F. V. S.; Menezes, J. B.; Guimarães, A. A.; Souza, P. A.; Simões, A. N.; Souza, G. L. F. M. Armazenamento do melão amarelo, híbrido RX20094, sob temperatura ambiente. Horticultura Brasileira, v.22, n.1 p.76-79, 2004.

Oliveira, O.; Maia, C. E. Qualidade físico-química da água para a irrigação em diferentes aqüíferos na área sedimentar do Estado do Rio Grande do Norte. Revista Brasileira de Engenharia Agrícola e Ambiental, v.2, n.1, p.17-21, 1998.
Souza, E. R.; Levien, S. L. A.; Medeiros, J. F. de; Porto Filho, F. Q.; Gheyi, H. R.; Sousa Neto, E. R.; Silva Júnior, M. J. Crescimento de melão irrigado com águas de diferentes níveis de salinidade. Caatinga, v.16, n.1/2, p.31-38, 2003.

USSL Staff - United States Salinity Laboratory. Diagnosis and improvement of saline and alkali soils. Washington: Department of Agriculture, 1954. 160p. Handbook 60 